\title{
The Rise and Reign of the Loser: \\ Emotionological Culture of the 1980S Red Sox
}

By Allison Wilkinson

"All men are mortal, and therefore all men are losers; our profoundest loyalty goes out to the fallible." - John Updike ${ }^{1}$

The Boston Red Sox and their fans had a long, complex relationship marked by fierce loyalty and repeated disappointments. Over the course of the $20^{\text {th }}$ century, the Red Sox brand cultivated a sense of destiny driven by losing; however, it did not start out this way. Following their inception in 1901, the Red Sox blazed on to the scene, winning five World Series in under twenty years. A hero in many baseball legends, George Herman "Babe" Ruth, carried the team on his shoulders. In 1920, under the guise of not wanting the team centered on a single individual, owner Henry Frazee sold Ruth to the team's soon-to-be bitter rival, the New York Yankees. ${ }^{2}$ This singular event was thought to have catalyzed a near century without a World Series title and set the Red Sox destiny. The deep-seeded betrayal fans carried as a result led to a wary balance between the organization and their fans for generations to come, despite their devotion. Subsequently, the Red Sox initially suffered, later endured, and finally embraced an existence as the epitomized and eternal losers. By the 1980s, the team had a well-established and invested fan base. In that decade, the Red Sox organization had a paradoxical and unique task in selling a team to a fan base that did not want or need to be sold to. The fans proved their investment to the team by their constant attendance through the dismal

1 Glenn Rifkin, "How the Boston Red Sox Touch All the Branding Bases," strategy \& business, October 1, 1999, Accessed May 1, 2015.

2 “Injustice to Keep Ruth, Says Frazee” The Sun, January 5, 1920, accessed June 2, 2015, Library of Congress. 
losing years and pushed back against marketing ploys. The issue at hand then was a matter of Peter and Carol Stearns' theory of emotionology. Emotionology is a term used to encapsulate "the attitudes and standards that a society, or a definable group within a society, maintains toward basic emotions and their expression; ways that institutions reflect and encourage these attitudes in human conduct." ${ }^{3}$ In order to understand the gravity of the Stearns' theory, the Red Sox must be thought of as more than a mere sports team, but rather as a definable culture in itself. The team and the culture surrounding it offered a channel for all of the most profound emotions to be expressed. These emotions were allowed, encouraged, and expected. The Stearns' addressed sports as "providing outlets for emotions not readily tolerated in other spheres." ${ }^{4}$ The combination of the expectations of the fan, seen through the team's popular histories and periodicals from the time, and the facilitation of these expectations by the team, by way of their seasonal records and marketing, allowed for the predominance of a society of fandom in Boston framed around a losing culture. I maintain that there was a distinct emotionological culture attached to the Red Sox institution, as seen through three representative manifestations: frustration when fans attempted to uphold their standards against what they saw as infringements upon the sanctity of their fandom, tragedy when the team faced their most monumental defeat, and optimism embodied by the achievements of individual players and the everlasting Fenway Park. The Red Sox organization directly and indirectly enabled their fans to develop these attitudes through their marketing tactics, performance, and venue.

Existing literature regarding the Boston Red Sox consists primarily of popular histories that acknowledged emotions of frustration and optimism without truly grasping the implications of their display. Works like that of Michael Borer in Faithful to Fenway: Believing in Boston, Baseball, and America's Most Beloved Ballpark or Derek Catsam's article "On Fenway, Faith, and Fandom:

3 Peter N. Stearns and Carol Z. Stearns "Emotionology: Clarifying the History of Emotions and Emotional Standards," The American Historical Review Vol. 90, no. 4, (October 1985).

4 Stearns, Peter N. and Carol Z. Stearns, ed. Emotion and Social Change: Toward a New Psychohistory (New York, N.Y.: Holmes \& Meier, 1988), 13. 
A Red Sox Fan Reflects" discussed sociological and surface level displays of emotion. ${ }^{5}$ They focused more on the emotions themselves, rather than the effects and attitudes they impart on the Red Sox institution. Their analyses were useful and necessary in establishing that an emotional culture did in fact exist, but they were reading into the nuances of these emotions that give the full breadth of Red Sox emotional history.

\section{Frustration - Seeing Red}

From their research, Stearns and Stearns found that a society "encounters its most serious emotional issues in areas where standards are changing." ${ }^{\prime 6}$ In the case of the Red Sox, the standard of success, or lack thereof, certainly did not change; rather, how the team chose to communicate with 'Red Sox Nation' did. ${ }^{7}$

In March 1984, The Boston Red Sox enacted an audacious marketing move by launching their own cable network with little notice to the fans. New England Sports Network, or NESN for short, was a premium broadcast channel of which the Red Sox owned a significant holding. It monopolized the regional airwaves and broadcast a majority of the Red Sox regular season games. Their choice of debut was especially brazen, as it came in the spring immediately following the Red Sox' most dismal finish in nearly two decades. ${ }^{8}$ Fans saw the channel less as a new outlet towards watching games and more as a blockade to their relationship with the team. For years the fans had devoured the typical baseball fodder: t-shirts, caps, programs, yearbooks, and magazines. To them, a television network was different. It was not a manifestation of team pride or a tangible feeling of connection and possession of the team; in fact, it was very much the opposite.

5 Michael I. Borer, Faithful to Fenway: Believing in Boston, Baseball, America's Most Beloved Ballpark (New York: New York University Press, 2008), accessed April 15, 2015, ProQuest ebrary; Derek Catsam “On Fenway, Faith, and Fandom: A Red Sox Fan Reflects” Baseball and American Culture: Across the Diamond, edited by Edward J. Rielly, (New York: Haworth Press, 2003).

6 Stearns, Emotion and Social Change, 17.

7 Nathan Cobb, “Baseball Border War; In Milford, Conn., Geography Brings Sox And Mets Fans; Cheek

To Jowl,” The Boston Globe, October 20, 1986, accessed April 27, 2015, ProQuest Newsstand.

8 Major League Baseball, “Year by Year results," Boston Red Sox, 2015, accessed April 15, 2015. 
On the very day of its launch, Boston Globe columnist Leigh Montville made his frustration known in the piece, "Red Sox on pay TV? I don't like it." In Boston, where the media was as much a fan as those in the seats, Montville's vocal opposition emphasized the emotion-driven relationship the Red Sox had with their fan base. For a team that had historically performed poorly, it was the enduring fans that kept their franchise alive. As such, fans felt they deserved respect from the organization for coming back year after year. Fans took the notion of paying for games, that used to be free, as insult. Montville, a weekly sports columnist and Connecticut native, was a single representative and voice of this much larger community. A community that planned its days and nights around the baseball broadcast. The Globe, Boston's major newspaper, catered directly to this demographic. In a humorously dramatic tone that carried throughout the piece, Montville described "it [was] as if there suddenly [were] a charge for air. Or sunshine. Or the time of day." ${ }^{10}$ While hyperbolic, he believed he conveyed the attitude of many fans; the Red Sox were central to life in New England and this charge was an affront of considerable measure. It tipped the scales in favor of the franchise over the fan. He sardonically painted the network as one destined to fail and saw the Red Sox network as a betrayal to the steadfast fans.

In a sense, this public and vehement opposition hinted at what the Red Sox sought in the introduction of the network. The overriding tone of Montville's piece, other than frustration, was passion for the Red Sox. This dedication, in the author and others like him, was exactly what the Red Sox hoped to capitalize on in broadcasting from their own channel. The "marketing hoo ha," as Montville called it, may very well have been the Sox trying to reinvigorate their market after their poor finish in 1983. The organization failed to remember that the fans motivations were not fueled by wins and losses, but by pure devotion to watching the team regardless of the outcome.

As reflected by Montville's impassioned piece, the fans felt they had some

9 Leigh Montville, "Red Sox on pay TV? I don't like it," The Boston Globe, March 21, 1984, accessed April 27, 2015. ProQuest Newsstand.

10 Montville, "Red Sox on pay TV?" 
kind of clout with the Red Sox and were aggravated when it seemed they were being slighted. They maintained ownership of the team through their fandom. To buy a cap or a magazine was to possess a part of the culture and to identify as part of a larger entity; however, the network took away the basis of that fan fraternity, the team and its games, and turned it for profit. What had previously been available to all would be limited to those who could and would pay. To sell out and join the mass media circus was not, in the fans' eyes, the way of a team so enveloped in history. Serving those diehard fans that proselytized tradition and touted their emotionological principles proved to be a difficult task, especially in a decade where the shift towards mass media was imminent. The immense frustration exhibited by the fans in regards to NESN gave an interesting look into their place within the Red Sox institution. In any conventional sport setting, fans would typically garner frustration at their team continuously losing; however, as Red Sox fans had come to expect this, they channeled their frustration into pushing back against new media. Their reactions were quick and agitated without considering the benefits of such a network. The Red Sox organization, on the other hand, made it clear that this network was not going anywhere. NESN, despite initial fan pushback, continued and eventually thrived, highlighting the ability for the fans' emotionological culture to develop in the face of change. This attempt at reinvigoration marked one of the major tensions between the organization and fans during the decade. As the "80s progressed, NESN remained the only marketing shakeup that impacted Sox culture, but competitively the team itself made a leap that had the ability to fundamentally change the culture forever.

\section{Tragedy - Sox Quest for Six}

The Sox journey towards their elusive sixth World Series title was a painful one and perfect exhibition of the team and fan's tragic sensibility. After World Series heartbreaks in 1946 and 1967, both of which ended in a crushing Game 7 defeat, two distinct themes could be seen: the Red Sox were not going to win, no matter how promising they were, and the fans would still be there, 
no matter the magnitude of loss. ${ }^{11}$ The team carried these commandments into the chaotic first half of the 1980s, where year after year the team found themselves amassing win-loss records including 83-77, 78-84, and 81-81. ${ }^{12}$ The decade was rough, but had its glimmering diamond in the 1986 season. The team made a glorious run at baseball's biggest prize. They rebounded in the Championship series in dramatic fashion and brought that flair with them to the big stage. ${ }^{13}$

Once they reached the Series itself, the team had multiple chances to clinch, but failed to seize their opportunities, seemingly reaffirming the institutionalized expectation of a disastrous end. In a bitter irony, prior to Game Six, Boston Globe contributor David Margolick noted that the Red Sox, "embody something else: the epic, ennobling sense of tragedy. There is, after all, something far grander about hopes dashed than hopes satisfied." ${ }^{14}$ Generations of fans were ingrained with this notion; many had been raised with it. For 68 years, the Red Sox had continually disappointed in the end, and while no fan was going to venture to say that they hoped the team lost, they would not be surprised if they did. In Boston baseball culture, it was not about the wins and the losses in the moment, it was the enigmatic, hopeful future that kept the fans coming back.

The fans expectation of loss was an interesting cultural phenomenon in the world of sports. As Yale President, eventual Baseball Commissioner, and Red Sox fan Bart Giamatti once proclaimed, "I almost think Boston fans don't want to win it all. They'd rather have winning out there as a shining ideal."15 Though the promise of a shining ideal is one explanation, Giamatti's argument had an added assumption of fear. Red Sox fans of the '80s only knew

11 Ivor-Campbell, Frederick. "Boston Red Sox," Encyclopedia of Major League Baseball Team Histories: American League, Edited by Peter Bjarkman (Westport, CT: Meckler, 1991), 34-35.

12 Major League Baseball, "Year by Year results," Boston Red Sox, 2015, accessed April 15, 2015, http:// mlb.mlb.com/bos/history/year_by_year_results.jsp.

13 Campbell, 40-41.

14 David Margolick, "What if the Red Sox Win?" The New York Times, October 25, 1986, accessed May 1, 2015, ProQuest Newsstand.

15 Ken Burns, Ken Burns: Baseball, Netflix, directed by Ken Burns (New York: PBS, 1994); Campbell, 42. 
losing and the innumerable unknown variables that could be affected by a title would prove daunting to anyone who grew up with the team. Would star players move on to a richer team? Would a new stadium be proposed? This is where the overwhelming sense of emotionology comes into play. Stearns claimed that this theory was necessary, "to distinguish between professed values and emotional experience." ${ }^{16}$ In sporting culture, the end goal is to win. Yet, Red Sox fans did not abide by this rule and their emotions were exhibited elsewhere. The team's history had allowed for the acceptance of and subconscious comfortability with losing.

The Red Sox would, yet again, confirm their tragic sensibility and inexplicably fail to come up with the win. They came excruciatingly close, bringing the Mets to their final strike, before Mookie Wilson's seemingly fateful at bat. Wilson fouled off pitch after pitch, and taunted Red Sox fans from, what betrayed their typical outlooks, an inevitable victory. Wilson finally made contact, it headed down the first base line towards Bill Buckner, a career .998 fielding first baseman, and the ball rolled under his glove. The Mets went on to win the game and, the next night, become World Series champions. ${ }^{17}$ This was the clearest instance of the Red Sox self-fulfilling prophecy, to come the closest any team had come to victory without actually achieving it. ${ }^{18}$ In true Red Sox fashion, the city held a parade to honor the team following yet another Game 7 defeat in which 750,000 fans turned out. ${ }^{19}$ To lose a World Series in which you were ahead was to be the biggest loser of them all in the pessimistic minds of many sports fans; to come so close, yet land so far. This loss was difficult, especially with how close the trophy came to residing in, "the sport's capital of the world," ${ }^{20}$ but deep down, fans expected it and took it in stride. They knew that another season of hope was just around the corner.

\footnotetext{
16 Stearns, "Emotionology."

17 Bill Buckner, Catching Hell, TV, directed by Alex Gibney (Los Angeles: ESPN, 2011).

18 Dan Shaughnessey, "One Strike Away: The standard for booting victory is set," The Boston Globe, October 22, 2004. ProQuest Newsstand.

19 Matthew L. Wald "Boston Enfolds its Heroes, Waiving Deplorable Act," The New York Times, October 30, 1986. ProQuest Newsstand.

20 Wald, "Boston Enfolds its Heroes."
} 


\section{Optimism - Motives and Monsters}

Despite the irksome tactics of the marketing team and monumental loss in the 1986 World Series, the overarching attitude of Red Sox fans in the 1980s and throughout history was an unfathomable optimism. For an area so familiar in tasting successes that became near misses, fans were expected to be there, rooting on the team with facetious bitterness, when springtime rolled around again. This sanguine outlook was stimulated by individual player success and the continuous charisma of Fenway.

The standout characters of the 1980s helped sustain interest and encourage hope in an especially bleak era. Players such as Jim Rice and Wade Boggs found ways to succeed individually, with Rice having a third straight season with 100 runs batted in and Boggs winning the batting title (both in 1985). ${ }^{21}$ A fresh-faced Texan named Roger Clemens had something to prove following two seasons of arm trouble. And prove himself he did, ringing up twenty strikeouts in a single game on April 29 $9^{\text {th }}, 1986$ and breaking a nine inning game record that had held for 102 years. ${ }^{22}$ These exceptional accomplishments defied the typical ideas associated with a losing team and became legends amongst the fans. The players became pop culture icons, with Boggs's peculiar superstitions and Clemens down-home, Southern charm making national headlines. ${ }^{23}$ The players of note were highlighted and profiled in team programs and magazines. ${ }^{24}$ When the Sox predictably came up as losers at the end of the season, the fans enjoyed watching it happen and rooted for those who provided the victories and awards the team would get. The players and their singular successes became flares of excitement for the future and incarnations of optimism against all history and reason; however, the continual beacon of hope for the Red Sox Nation was its home, Fenway Park.

21 Dick Bresciani ed., Boston Red Sox 1986 1st Edition Official Scorebook Magazine (Boston: Boston Red Sox Publishing, 1986), 9-11.

22 Campbell, 40.

23 Ira Berkow, "Night to Remember is No Night to Sleep," The New York Times, May 1, 1986, accessed May 1, 2015. ProQuest Newsstand.

24 Bresciani, Boston Red Sox 1986, 9-11. 
Part of the everlasting appeal of the Red Sox and a large contributing factor to their sustained fan base has been "Friendly Fenway." ${ }^{25}$ The park, strategically placed in the Fens neighborhood of Boston, opened on April 20 th $1912 .{ }^{26}$ The community, ideologically and physically, built up around Fenway Park. It led a typical existence until 1933 when, in an attempt to recapture fan interest, Yawkey, the new owner, painted Fenway a unique shade of green. Thus interminable icons such as the Green Monster, Fenway's giant, unparalleled left field wall, were born. ${ }^{27}$ Over the decades, these quirks became images that the fans could attach their sentiments to. The Monster became as much of a participant in the game as left fielders like Carl Yastrzemski, Ted Williams, and Jim Rice. The mere experience of setting foot in the hallowed grounds of Fenway Park was and is a rite of passage to all baseball fans. It is to Red Sox fans what the Vatican is to the Catholic religion: a place of passion, tears, and admiration from many, even those outside the faith.

The park's multigenerational existence made it the perfect setting for the exhibition of the Red Sox emotionological culture. The familial bonds strengthened in the park added a further layer to the importance of the team and its venue. As one fan claimed, "my great-grandfather, grandfather, father, and myself have all seen games there, and have probably sat behind the same beam!" ${ }^{28}$ Fenway embedded itself in the very being of Boston fans. As a result of its enduring presence, Fenway Park became the image of optimism. The field's aura even prompted a marketing venture that had never been done before in baseball. The Sox decided to honor their most consistent member with a celebration of its $75^{\text {th }}$ anniversary in $1987 .{ }^{29}$ No other park in major league baseball had been around as long, nor had they become as iconic. The green walls and Citgo sign were there to watch over the fans and provided a level of

\footnotetext{
25 Rifkin.

26 Rifkin.

27 “At Age 75, Fenway Park Has Lost None of Its Charm,” The Los Angeles Times, May 3, 1987, accessed April 27, 2015. ProQuest Newsstand.

28 Borer. Faithful to Fenway, 181.

29 Major League Baseball, “Timeline.” Fenway Park Living Museum Fund. 2015, accessed April 15, 2015, http://mlb.mlb.com/bos/fenway-park-living-museum/timeline/.
} 
dependability in the midst of the team's unpredictable performance.

The Red Sox' consistent level of loss leaves those outside the fandom wondering why fans continue their ardent support of the team. Scholars of sports psychology have grappled with questions similar to this for decades and have varying interpretations. As Lloyd Reynolds Sloan cited in his chapter "The Motives of Sports Fans," fans are attracted to the game as it "teach[es] us of life by letting us witness life's values or our culture's numerous values being portrayed." ${ }^{30}$ On top of values such as hard work, personal and collective achievement, and adaptability, the Red Sox fans had an added layer of constructs including loss and perseverance. Margolick, in his sentimental reflection on the team in 1986, said it best:

\begin{abstract}
Sure, the Red Sox are not the embodiment of success, but in their current character they represent many other more-enduring values. They embody perseverance, reminding us annually that even with the best of efforts we often come up short and simply must resolve to do better. They embody resiliency and optimism, the conviction that no matter how bad things can be one year, spring training is just around the corner. We love the Sox not because we're masochists but because, in all of their doomed rallies in all their ninth innings of all their seventh games, they mirror our own struggles and disappointments and dreams. ${ }^{31}$
\end{abstract}

To witness the outstanding athletes on the field celebrating the small successes in day-to-day wins and facing the enormous losses in the Fall Classic was a reminder that they were human, just like any fan. ${ }^{32}$ Sloan's subsequent arguments revolve around the idea that "idolatry of victory in sports is an undeniable fact" and that fans could fulfill achievement needs by indulging in their team's successes. ${ }^{33}$ The Red Sox serve as a true counterargument to this asser-

30 Lloyd Reynolds Sloan, “The Motives of Sports Fans." Sports, Games, and Play: Social and Psychological Viewpoints. Jeffrey H. Goldstein, ed. (London: Psychology Press, 1979), 191.

31 Margolick, "What if the Red Sox Win?"

32 Another name for the World Series.

33 Sloan "The Motives of Sports Fans,"192-193. 
tion. The team lost and fans turned out in droves. Even in their most dismal season of 1984 , the team drew attendance of $1,782,285$, almost 70,000 fans above the American League average. The season after the tantalizingly close World Series title, attendance spiked to 2,147,641, a whopping 349,589 over the average. ${ }^{34}$ The numbers serve as further proof that the fans would come, win or lose. For Red Sox fans, it was more the idolatry of the almost-victory. The underlying anticipation of loss allowed for fans to simply enjoy the game with measured hope and without any particularly grand expectations.

\section{That's The Game}

The difficulties the Red Sox faced in the 1980s were perceptually different from any conventional ideas regarding sports teams. Success for the Red Sox was not marked by the standard win-loss record, but rather by the continued support of their fan base. Without going so far as to analyze the emotional implications, Catsam realized and reflected upon the matchless nature of Red Sox fandom, "They are more than a favorite sports team. They are more like a cultural institution." ${ }^{35}$ The awareness of Red Sox fans of their belonging to something greater than simple sports fanaticism indicates the power of the culture they developed. The fans built their emotional constructs and dedicated their "profoundest loyalties" around a team that was infallible in their fallibility. From these constructs came the foundations for the rise and reverence of the Red Sox losing legacy. This culture encapsulated a wide and varied range of sentiments. The spectrum of emotions ranged from frustrations, tragic sensibility, and fervently held optimism. Team performance, even with the expectation of loss, was met with a 'we'll get them next year' attitude, best summarized by Frederick Ivor-Campbell when he wrote "losing is winning as it leads to hope." ${ }^{36}$

In 2004, after 86 years, Red Sox fans no longer had to wonder what lie after the mystical World Series title as they clinched the Commissioner's Tro-

34 Baseball Almanac, "Boston Red Sox Attendance Data," Baseball Almanac Attendance Data.

35 Catsam, "On Fenway, Faith, and Fandom," 25.

36 Campbell, 42. 
phy. ${ }^{37}$ in a four game sweep of the St. Louis Cardinals. They then went on to become one of the most successful teams of the early $21^{\text {st }}$ century, becoming the first to win three World Series titles in a decade. ${ }^{38}$ This success prompted a curious emotionological dissonance for the modern Red Sox nation, and an interesting study for emotional historians, as they are now composed of generations raised in the era marked by massive defeat and those raised in the era marked by glorious victory.

37 The Commissioner's Trophy is the trophy given out each year by the Commissioner of Major League Baseball to the team that wins the World Series.

38 Soumya Karlamangla, "Boston celebrates Red Sox win, remembers marathon bombings,"The Los Angeles Times, November 2, 2013, accessed June 2, 2015, http://articles.latimes.com/2013/nov/02/nation/ la-na-nn-boston-red-sox-marathon-20131102. 


\section{BIBLIOGRAPHY}

“At Age 75, Fenway Park Has Lost None of Its Charm." The Los Angeles

Times, May 3, 1987. Accessed April 27, 2015. ProQuest Newsstand.

Baseball Almanac. "Boston Red Sox Attendance Data." Baseball Almanac Attendance Data.

Berkow, Ira. "Night to Remember is No Night to Sleep," The New York

Times, May 1, 1986. Accessed May 1, 2015. ProQuest Newsstand.

Borer, Michael I. Faithful to Fenway: Believing in Boston, Baseball, America's

Most Beloved Ballpark. New York: New York University Press, 2008.

Accessed April 15, 2015. ProQuest ebrary.

Buckner, Bill. Catching Hell.TV. Directed by Alex Gibney. Los Angeles:

ESPN, 2011.

Burns, Ken. Ken Burns: Baseball. Netflix. Directed by Ken Burns. New York: PBS, 1994.

Bresciani, Dick, ed. Boston Red Sox $19861^{\text {st }}$ Edition Official Scorebook Magazine.

Boston: Boston Red Sox Publishing, 1986.

Catsam, Derek. Baseball and American Culture: Across the Diamond. Edited by Edward J. Rielly. New York: Haworth Press, 2003.

Cobb, Nathan. "Baseball Border War; In Milford, Conn., Geography Brings Sox And Mets Fans; Cheek To Jowl," The Boston Globe, Oct 20, 1986. Accessed April 27, 2015. ProQuest Newsstand.

Goldstein, Jeffrey H., ed. “The Motives of Sports Fans.” Sports, Games, and Play: Social and Psychological Viewpoints. London: Psychology Press, 1979.

Ivor-Campbell, Frederick. "Boston Red Sox," Encyclopedia of Major League Baseball Team Histories: American League. Edited by Peter Bjarkman. Westport, CT: Meckler, 1991, 16-42.

Karlamangla, Soumya. "Boston celebrates Red Sox win, remembers marathon bombings." The Los Angeles Times, Nov 2, 2013. Accessed June 2, 2015. http://arti 
cles.latimes.com/2013/nov/02/nation/la-na-nn-boston-red-sox-mara thon-20131102.

Major League Baseball. “Timeline.” Fenway Park Living Museum Fund. Last modi fied 2015. Accessed April 15, 2015. http://mlb.mlb.com/bos/fenway-park-liv ing-museum/timeline/.

Major League Baseball. "Year by Year results." Boston Red Sox. Last modified 2015. Accessed April 15, 2015.http://mlb.mlb.com/bos/history/year_by_year_results.jsp.

Margolick, David. "What if the Red Sox Win?.” The Nerw York Times, October 25, 1986. Accessed May 1, 2015. ProQuest Newsstand.

Montville, Leigh. "Red Sox on pay TV? I don't like it," The Boston Globe, March 21, 1984. Accessed April 27, 2015. ProQuest Newsstand.

Rifkin, Glenn. "How the Boston Red Sox Touch All the Branding Bases.," strategy \& business, October 1, 1999. Accessed May 1, 2015. http://www.strategy-business. com/article/13714?gko=7e910.

Shaughnessey, Dan. "One Strike Away: The standard for booting victory is set," The Boston Globe, October 22, 2004. ProQuest Newsstand.

Stearns, Peter N. and Carol Z. Stearns. "Emotionology: Clarifying the History of Emotions and Emotional Standards," The American Historical Review 90, no. 4 (October 1985). JSTOR. . Emotion and Social Change: Toward a New Psychohistory. New York: Holmes \& Meier, 1988.

Wald, Matthew L. "Boston Enfolds its Heroes, Waiving Deplorable Act," The New York Times, October 30, 1986. ProQuest Newsstand.

"Injustice to Keep Ruth, Says Frazee." The Sun, January 5, 1920. Accessed June 2, 2015. Library of Congress. 